\title{
Складові професійно-прикладної фізичної підготовки майбутніх фахівців правоохоронної діяльності
}

\author{
Марина Гресь, Олена Андрєєва
}

Національний університет фізичного виховання і спорту України, Київ, Україна

Анотація. У статті подано інформацію про рівень фрізичної підготовленості майбутніх фахівців правоохоронної діяльності та складових їхньої професійно-прикладної фрізично підготовки. Мета. Охарактеризувати складові професійно-прикладної фрізичної підготовки майбутніх фрахівців правоохоронної діяльності. Методи. Аналіз фрахової науково-методичної літератури та документальних матеріалів, педагогічне тестування, методи математичної статистики. Результати. Загальний рівень фрізичної підготовленості вказує на те, що більшість юнаків і дівчат мають середній рівень фізичної підготовленості, високий рівень спостерігається лише у дівчат, з низьким рівнем фрізичної підготовленості юнаків на 4,6 \% більше, ніж дівчат. Досить мала кількість юнаків і дівчат, що не перевищує навіть 15,0 \% мають достатній рівень фізичної підготовленості. Отримані в ході дослідження результати свідчать про необхідність перегляду існуючої програми з фрізичного виховання у закладах вищої освіти та розробки і впровадження сучасних засобів для розвитку основних рухових якостей студентів.

Ключові слова: студенти, професійно-прикладна фрізична підготовка, фрізична підготовленість.

\section{Maryna Hres, Olena Andrieieva}

\section{COMPONENTS OF PROFESSIONAL AND APPLIED PHYSICAL TRAINING OF FUTURE LAW ENFORCEMENT PROFESSIONALS}

Abstract. The article provides information about the level of physical fitness of future law enforcement professionals and components of their professional and applied physical training. Objective. To characterize the components of professional and applied physical training of future law enforcement professionals. Methods. Analysis of special scientific and methodological literature and documentary materials, pedagogical testing, and the methods of mathematical statistics. Results. The overall level of physical fitness indicated that most of young men and women had an average level of physical fitness, a high level was observed only in women, and the number of men with a low level of physical fitness was $4,6 \%$ higher than that of women. A relatively small number of young men and women not even exceeding $15,0 \%$ had a sufficient level of physical fitness. The results of the study indicate the need to revise the existing program of physical education in higher education institutions and to develop and implement modern means for the development of basic motor skills in students.

Keywords: students, professional and applied physical training, physical fitness.
Hres M., Andrieieva 0. Components of professional and applied physical training of future law enforcement professionals. Theory and Methods of Physical education and sports. 2021; 3: 55-59 DOI: 10.32652/tmfvs.2021.3.55-59
Гресь М., Андрєєва О. Складові професійно-прикладної фрізичної підготовки майбутніх фрахівців правоохоронної діяльності.

Теорія і методика фрізичного виховання і спорту. 2021; 3: 55-59

DOI: $10.32652 /$ tmfvs.2021.3.55-59
Вступ. Проблема якісної підготовки майбутніх правоохоронців до професійної діяльності завжди була актуальною, а сьогодні в умовах реформації правоохоронних структур набула особливої значущості [6]. Професійна діяльність фрахівців правоохоронних органів передбачає вирішення завдань, пов'язаних з ризиком для життя, тому їхня особиста безпека великою мірою залежить від фрізичної та професійної підготовленості. Дослідники зазначають, що однією 3 найважливіших складових професійної діяльності правоохоронця $є$ здатність його організму до подолання впливу несприятливих чинників навколишнього середовища $[6,8]$. Одним із вагомих чинників посилення опірності організму до дії несприятливих чинників професійної діяльності та навколишнього середовища $є$ високий рівень фізичної підготовленості правоохоронців. Науковці вказують, що виконання фрізичних вправ, покращуючи ффізичний розвиток, значно розширює функціональні можливості основних систем організму, зменшуючи при цьому негативний вплив чинників професійної діяльності [9].

Фізичне виховання у закладах вищої освіти - не лише важливий елемент всебічного розвитку студентів, збереження та зміцнення здоров'я, фізичного і духовного вдосконалення, а і якісна підготовка до майбутньої професійної діяльності. Важливу роль у зв'язку з цим має забезпечення необхідного рівня професійної готовності майбутніх фрахівців, до якої входять фозична підготовленість, тренованість, роботоздатність, розвиток професійно важливих умінь, навичок і якостей [9]. Дослідниками зазначається, що нині відбувається суттєве зниження рівня рухової активності студентської молоді, зниження її мотивації до занять фізичними вправа- 
ми, і, як наслідок - рівня фрізичної підготовленості [1-5, 7, 10-13].

Варто зазначити, що комплексних досліджень 3 оцінювання фрізичної підготовленості майбутніх фрахівців правоохоронної діяльності вкрай недостатньо. Отже, можна говорити про актуальність досліджуваної теми і з теоретичної, і з практичної площин.

Дослідження виконано відповідно до плану НДР НУФВСУ на 2021-2025 рр. за темою «Теоретичні та технологічні засади оздоровчорекреаційної рухової активності та здорового способу життя різних груп населення» (номер держреєстрації 0121U107534).

Мета дослідження - охарактеризувати складові професійно-прикладної фрізичної підготовки майбутніх фрахівців правоохоронної діяльності.

Методи дослідження: аналіз спеціальної науково-методичної літератури, документальних матеріалів, педагогічне тестування, методи математичної статистики.

Результати дослідження та їх обговорення. У ході дослідження ми використали тести для щорічного оцінювання рівня фрізичної підготовленості населення України, які $\epsilon$ обов'язковими і $€$ основою нормативних вимог у закладах вищої освіти. Додатково визначили статичну рівновагу, силу м'язів черевного преса та вибухову силу. Такий комплексний підхід у тестуванні дав можливість виявити слабкі і сильні сторони у розвитку рухових якостей юнаків і дівчат. Статистичне опрацювання отриманих результатів проводили з використанням методів математичної статистики.

Дослідження проводили на базі Житомирського державного технологічного університету. У педагогічному експерименті брали участь 259 студентів, 3 них - 114 юнаків та 145 - дівчат, які здобувають вищу освіту за спеціальністю «Правоохоронна діяльність».

Результати оцінювання розвитку рухових якостей юнаків та дівчат подано у таблиці 1 .

Статистична обробка отриманих даних у рухових тестах показала, що у юнаків і дівчат такі якості, як швидкість, спритність, сила і витривалість
Т а б л и ц я 1. Середньостатистичні результати розвиту рухових якостей юнаків і дівчат $(\mathrm{n}=259)$

\begin{tabular}{|l|c|c|c|c|c|c|c|}
\hline \multicolumn{1}{|c|}{ Показник } & $x$ & S & Me & $25 \%$ & $75 \%$ & V, $\%$ \\
\hline \multicolumn{7}{|c|}{ Юнаки (n = 114) } \\
\hline Біг 100 м, с & 14,3 & 0,94 & 14,2 & 13,8 & 14,7 & 6,6 \\
\hline Човниковий біг 4 × 9 м, с & 9,82 & 0,61 & 9,81 & 9,40 & 10,20 & 6,2 \\
\hline Стрибок у довжину з місця, см & 231,8 & 17,50 & 233,5 & 221,0 & 245,0 & 7,6 \\
\hline Рівномірний біг 3000 м, хв, с & 14,32 & 0,98 & 14,20 & 13,45 & 15,12 & 6,8 \\
\hline $\begin{array}{l}\text { Нахил тулуба вперед з положення сидя- } \\
\text { чи, см }\end{array}$ & 7,0 & 2,68 & 6,0 & 5,0 & 9,0 & 38,1 \\
\hline Піднімання тулуба в сід за 1 хв, разів & 38,6 & 8,04 & 39,5 & 35,0 & 43,0 & 20,9 \\
\hline Стрибок у висоту, см & 25,8 & 5,16 & 26,0 & 21,0 & 30,0 & 20,0 \\
\hline Ускладнена проба Ромберга, с & 9,9 & 3,31 & 9,0 & 7,5 & 12,0 & 33,4 \\
\hline \multicolumn{7}{|c|}{ Дівчата (n $=145)$} \\
\hline Біг 100 м, с & 15,9 & 0,65 & 15,9 & 15,4 & 16,5 & 4,1 \\
\hline Човниковий біг 4 × 9 м, с & 11,2 & 0,47 & 11,2 & 10,8 & 11,5 & 4,2 \\
\hline Стрибок у довжину з місця, см & 190,1 & 13,52 & 188,0 & 179,0 & 202,0 & 7,1 \\
\hline Рівномірний біг 2000 м, хв., с & 11,52 & 0,77 & 11,45 & 11,21 & 12,18 & 6,7 \\
\hline $\begin{array}{l}\text { Нахил тулуба вперед з положення сидя- } \\
\text { чи, см }\end{array}$ & 12,5 & 4,47 & 12,0 & 8,0 & 17,0 & 35,8 \\
\hline Піднімання тулуба в сід за 1 хв, разів & 32,5 & 6,47 & 32,0 & 30,0 & 36,0 & 19,9 \\
\hline Ускладнена проба Ромберга, с & 10,8 & 3,63 & 9,0 & 8,0 & 14,0 & 33,5 \\
\hline Стрибок у висоту, см & 20,7 & 2,83 & 21,0 & 18,0 & 23,0 & 13,7 \\
\hline
\end{tabular}

Т а б л и ц я 2. Зведена відомість результатів тестування фрізичної підготовленості юнаків і дівчат $(\mathrm{n}=259)$

\begin{tabular}{|c|c|c|c|c|c|}
\hline \multirow{2}{*}{ Тест } & \multicolumn{5}{|c|}{ Бал } \\
\hline & 5 & 4 & 3 & 2 & $\mathbf{0}$ \\
\hline \multicolumn{6}{|c|}{ Юнаки (n = 114) } \\
\hline Біг 100 м, с & 13 & 24 & 26 & 41 & 10 \\
\hline Човниковий біг $4 \times 9$ м, с & 10 & 23 & 37 & 33 & 11 \\
\hline Стрибок у довжину з місця, см & 6 & 28 & 18 & 55 & 7 \\
\hline Рівномірний біг 3000 м, хв, с & 4 & 16 & 38 & 40 & 16 \\
\hline Нахил тулуба вперед з положення сидячи, см & 4 & 15 & 13 & 32 & 50 \\
\hline \multicolumn{6}{|c|}{ Дівчата (n = 145) } \\
\hline Біг 100 м, с & 11 & 31 & 60 & 43 & 0 \\
\hline Човниковий біг $4 \times 9$ м, с & 13 & 25 & 50 & 34 & 23 \\
\hline Стрибок у довжину з місця, см & 9 & 36 & 38 & 62 & 0 \\
\hline Рівномірний біг 2000 м, хв, с & 15 & 16 & 49 & 43 & 22 \\
\hline Нахил тулуба вперед з положення сидячи, см & 6 & 15 & 36 & 36 & 52 \\
\hline
\end{tabular}


перебувають на достатньому рівні. В обох статевих групах спостерігається низький рівень розвитку гнучкості та статичної координації, а також швидкісно-силових якостей.

Слід також вказати на те, що серед юнаків спостерігається висока варіативність показників, які характеризують гнучкість, силу, вибухову силу, статичну координацію, що вказує на неоднорідність вибірки, а коефіцієнти варіації знаходяться в межах 20,0$38,1 \%$. Великий розмах значень у показниках гнучкості, які знаходяться в межах від мінімального (4 см) до максимального (14 см), у показниках статичної координації (від 3,9 до 17,5 c), у підніманні тулуба в сід (від 22 до 56 разів), у стрибках у висоту (від 18 до $35 \mathrm{~cm})$.

У дівчат висока варіативність спостерігається у показниках гнучкості, сили та статичної координації, коесріцієнти варіації знаходяться в межах 19,9-35,8 \%.

Аналіз результатів зведеної відомості юнаків і дівчат дає змогу більш детально проаналізувати розвиток рухових якостей. Як видно з таблиці 2, переважна більшість юнаків (36,0 \% $(\mathrm{n}=41))$ під час виконання тесту з бігу на 100 м, який характеризує розвиток швидкості, отримали 2 бали, лише $11,4 \%$ ( $=13$ ) юнаків виконали норматив на 5 балів, та були такі (8,8\% $(n=10))$, що взагалі не набрали жодного бала.

Результати тестування спритності показали, що переважна більшість юнаків $(32,5 \%(\mathrm{n}=37))$ отримали 3 бали, на 5 балів виконали 8,8\% ( $n=10)$ юнаків і не набрали жодного бала 9,7\% (n=11) осіб.

Індивідуальні результати у стрибках у довжину з місця у 48,2 \% ( $n=55)$ юнаків відповідали 2 балам, на 5 балів тест виконали 5,3 \% ( $n=6)$ осіб, взагалі не набрали жодного бала 6,1 \% $(\mathrm{n}=7)$ юнаків.

у переважної більшості юнаків $(35,1 \%(n=40))$ результати з бігу на 3000 м, які вказують на витривалість, відповідали 2 балам, 3,5\% (n=4) отримали 5 балів та 14,0\% (n=16) взагалі не набрали жодного бала.

Т а б л и ц я 3. Результати виконання тестів і нормативів фрізичної підготовленості юнаків і дівчат $(n=259)$

\begin{tabular}{|c|c|c|c|}
\hline Рівень & Юнаки (n=114), \% & Дівчата (n= 145), \% & Оцінка \\
\hline Високий & $0,0(n=0)$ & $1,4(n=2)$ & Відмінно \\
\hline Достатній & $9,6(n=11)$ & $13,8(n=29)$ & Добре \\
\hline Середній & $56,2(n=64)$ & $55,2(n=80)$ & Задовільно \\
\hline Низький & $34,2(n=39)$ & $29,6(n=43)$ & Незадовільно \\
\hline
\end{tabular}

Результати тестування гнучкості виявили 43,9 \% ( $\mathrm{n}=50)$ юнаків, які не змогли виконати цей тест і не отримали жодного бала, а 28,1 \% ( $\mathrm{n}=32)$ осіб набрали всього 2 бали. Відомо, що недостатній розвиток гнучкості може негативно впливати на координаційні здібності і бути однією з причин низького рівня спритності.

Аналіз зведеної відомості результатів фозичної підготовленості дівчат, представлених у таблиці 2, свідчать, що переважна більшість осіб під час виконання тестових завдань отримували 3 бали.

Під час виконання тесту з бігу на 100 м 41,4 \% (n=60) осіб, а це переважна більшість, отримали 3 бали, $7,6 \%$ ( $n=11)$ отримали 5 балів, на 2 бали виконали тест 29,7 \% ( $n=43)$ дівчат. Під час виконання нормативу 3 бігу $4 \times 9$ м 15,9\% $(n=23)$ дівчат не набрали жодного бала, 23,5 \% ( $\mathrm{n}=34)$ набрали всього 2 бали, переважна більшість $(34,5 \%(n=50))$ отримали 3 бали, а на 5 балів виконали норматив усього 9,0\% ( $n=13)$ дівчат.

Ступінь розвитку швидкісно-силових якостей у дівчат оцінювали за допомогою тесту «Стрибок у довжину 3 місця». Переважна більшість учасниць $(42,8 \%(n=62))$ виконали тест на 2 бали, на 5 балів виконали лише $6,2 \%(n=9)$ осіб. Для визначення ступеня розвитку витривалості було використано біг на 2000 м. На 5 балів виконали норматив 10,3 \% ( $\mathrm{n}=15)$ дівчат, найбільша кількість (33,7 \% (n = 49)) отримала 3 бали і не набрали жодного бала 15,2 \% ( $\mathrm{n}=22)$. Виконання тестового завдання «Нахил тулуба вперед 3 положення сидячи» вказує на ступінь розвитку рухливості хребта. Серед дівчат переважна більшість $(35,9 \%(n=52))$ під час вико- нання тесту не набрала жодного бала, $24,8 \%(n=36)$ набрали по 2 і 3 бали і лише 4,1\% (n=6) дівчат виконали норматив на 5 балів. Слід відмітити, що дівчата мають кращі результати 3 гнучкості та координації рухів, ніж юнаки, їм також властиві кращі показники швидкості та спритності, але низькі індивідуальні результати в обох статевих групах під час виконання рухових тестів не дали змогу отримати високі бали і вказують на необхідність пошуку ефективних засобів для розвитку та вдосконалення основних рухових якостей.

3 огляду на практичну діяльність фрахівців правоохоронних органів можна стверджувати, що від рівня фрізичної підготовленості великою мірою залежить ефективне вирішення оперативно-службових завдань. Також важливим критерієм професійної придатності фрахівців правоохоронних органів є оптимальний рівень фрізичної підготовленості, який визначає якість виконання посадових обов'язків. У таблиці 3 представлено узагальнюючі результати виконання тестів і нормативів юнаків і дівчат 3 визначенням рівня фрізичної підготовленості.

Для фахівців правоохоронних органів фрізична підготовленість є однією з головних складових професійноприкладної підготовки, тому що досить часто передбачає затримку правопорушників, які можуть чинити опір, а також здатність дати відсіч при нападі. Враховуючи специсріку даної просресії, фрахівці повинні ефрективно використовувати силові прийоми, спеціальні засоби та вогнепальну зброю для власної безпеки.

Висновки. Виконання складних профресійних завдань співробітника- 
ми правоохоронної ссрери неможливе без високого рівня фрізичної підготовленості. ї̈̈ роль є надважливою в навчально-виховному процесі студентів у період становлення їх як фахівців, просресійна діяльність яких безпосередньо пов'язана 3 екстремальними ситуаціями, котрі висувають максимально високі вимоги до фрізичної підготовленості, особистісних, морально-вольових, психічних та інтелектуальних якостей.

Вивчення особливостей професійної діяльності майбутніх фахівців правоохоронної сфрери свідчить про необхідність спрямованості процесу фізичної підготовки на комплексне вдосконалення фрізичних якостей, і його орієнтованості на підвищення фуннцціональних можливостей організму. Оцінювання фрізичної підготовленості студентів - майбутніх фахівців правоохоронної ссрери продемонструвала, що у юнаків і дівчат виявлено достатній рівень розвитку швидкості, спритності, сили і витривалості, а низький рівень зафріксовано у розвитку гнучкості та статичної координації, а також швидкісно-силових якостей.

Загальний рівень фрізичної підготовленості вказує на те, що більшість юнаків і дівчат мають середній рівень фізичної підготовленості, високий рівень спостерігається лише у дівчат, 3 низьким рівнем фрізичної підготовленості юнаків на 4,6 \% більше, ніж дівчат. Таку особливість можна пояснити тим, що дівчата свідомо обирають дану просресію і більш ретельно займаються фрізичними вправами. Досить мала кількість юнаків і дівчат, що не перевищує навіть 15,0%, мають достатній рівень фізичної підготовленості. Отримані результати вказують на необхідність перегляду існуючої програми 3 фрізичної підготовки у закладах вищої освіти та розробки і впровадження сучасних засобів для розвитку основних рухових якостей.

Перспективи подальших досліджень передбачають розробку програми професійно-прикладної фрізичної підготовки майбутніх фахівців правоохоронної діяльності з використанням засобів оздоровчого фрітнесу.

Конфлікт інтересів. Автори заявляють, що відсутній будь-який конфллікт інтересів.

\section{ЛІTЕРАТУРА}

1. Андреева E, Катерина У. Анализ мотивации студентов к внеучебным формам организации занятий по физическому воспи танию. Фізична активність, здоров'я і спорт. 2014:4:18-27.

2. Андрєєва 0, Кенсицька І. Лімітуючі та стимулюючі чинники формування цінностей здорового способужиття студентів. Молодіжний науковий вісник Східноєвропейського національного університету імені Лесі Українки 2017;26:37-42

3. Андрєєва 0, Садовський 0. Оцінка відношення студентів до організації процесу фізичного виховання у вищих навчальних закладах. Молодіжний науковий вісник Східноєвропейського національного університету імені Лесі Українки. 2014:15:31-5.

4. Андрєєва 0, Садовський 0. Рухова активність як складова рекреаційної культури студентів. Теорія і методика фріз. виховання спорту. 2016; 1:15-8.

5. Благій ОЛ. Андрєєва ОВ. Рухова активність як фактор формування здорово го способу життя учнівської молоді. Актуальні проблеми фрізичного виховання, реабілітації, спорту та туризму: матеріали III Міжнар. наук. практ. конф. Запоріжжя: КПУ; 2011:27, 28

6. Єфремова АЯ. Професійно-прикладна фізична підготовка в системі фізичного вихо вання вищих навчальних закладів залізничного профілю: навчальний посібник. Харків: УкрДУЗТ; 2018. 164 с.

7. Катерина УМ, Андрєєва ОВ. Соціально педагогічні передумови впровадження нав чально-оздоровчих комплексів в процес фізич ного виховання студентів. Молодіжний науко вий вісник Східноєвропейського національного університету ім. Лесі Українки. 2014;14:18-22.

8. Панкратов НС, Панкратов МС. Профес сионально-прикладная физическая подготовка, формирование профессионально важных двигательных качеств. Науковий часопис На ціонального педагогічного університету імені М.П. Драгоманова. 2018;1(95)18:43-6.

9. Ягодзінський ВП, Русанівський СВ, Безпалий СМ, Запорожанов ОВ, Юр'єв СО, Штома ВД. Розвиток силових якостей у курсантів у процес занять за системою «Кросфіт». Науковий часо пис Національного педагогічного університе ту імені М. П. Драгоманова. Серія № 15 Науково-педагогічні проблеми фізичної культури (фізична культура і спорт). 2020;2(122 20:198-201.

10. Andrieieva 0, Kashuba V, Carp I, Blystiv T, Palchuk M, Kovalova N, \& Khrypko I. As sessment of emotional state and mental activity of 15-16 year-old boys and girls who had a low level of physical activity. Journal of Physical Education and Sport. 2019; 19:1022-1029. https://doi. org/10.7752/jpes.2019.s3147

11. Imas YV, Dutchak MV, Andrieieva OV Kashuba V0, Kensytska IL, Sadovskyi 00. Mo dern approaches to the problem of values' formation of students' healthy lifestyle in the course of physical training. Physical education of students. 2018;22(4):182-9. DOI:10.15561/ 20755279.2018.0403
12. Hakman A Andrieieva 0 , Bezverkhnia $\mathrm{H}$, Moskalenko N, Tsybulska V, Osadchenko T, Filak Y. Dynamics of the physical fitness and circumference sizes of body parts as a motivation for selfimprovement and self-control in students. Journal of Physical Education and Sport. 2020;20(1):116122. https://doi.org/10.7752/jpes.2020.01015

13. Kashuba VA, Futorny SM, Andreeva EV. Modern approaches to the health of students in the process of physical education. Phys. education of students. 2012;5:50-58.

\section{LITERATURE}

1. Andrieieva E, Kateryna U. Analysis of students' motivation for extracurricular forms of physical education classes. Physical activity, health and sport. 2014;4:18-27.

2. Andrieieva 0, Kensytska I. Factors limiting and facilitating formation of healthy lifestyle values in students. Youth Scientific Journal Lesya Ukrainka Eastern European National University. 2017;26:37-42

3. Andrieieva 0, Sadovskyi 0. Assessment of students' attitude to the organization of physical education process in higher education institutions. Youth Scientific Journal Lesya Ukrainka Eastern European National University. 2014;15:31-5.

4. Andrieieva 0, Sadovskyi 0. Physical activity as a component of students' recreational culture. Theory and methods of physical education and sports. 2016; 1:15-8.

5. Blahii OL, Andrieieva OV. Physical activity as a factor affecting development of a healthy lifestyle in school students. Actual issues of physical education, rehabilitation, sports and turism: Proc. of the III Internat. scient.-pract. conf. Zaporizhzhia: CPU; 2011:27, 28.

6. Yefremova AYa. Professional and applied physical training in the system of physical education of higher education railway institutions: study guide. Kharkiv, Ukrainian State Railway Academy; 2018. 164 p.

7. Kateryna UM, Andrieieva OV. Sociopedagogical prerequisites for the introduction of educational and health-enhancing complexes in the process of physical education of students. Youth Scientific Journal Lesya Ukrainka Eastern European National University. 2014;14:18-22.

8. Pankratov NS, Pankratov MS. Professional and applied physical training, formation of professionally important physical abilities. Naukovyi chasopys of M.P.Dragomanov National Pedagogical University: 2018;1(95)18:43-6.

9. Yagodzinskyi VP, Rusanivskyi SV, Bezpalyi SM, Zaporozhanov OV, Yuriev SO, Shtoma VD. Development of strength abilities in cadets in the process of training using the CrossFit system. Naukovyi chasopys of M.P.Dragomanov National Pedagogical University. Series 15. Scientific and pedagogical problems of physical culture (Physical culture and sports). 2020;2(122)20: 198-201.

10. Andrieieva O, Kashuba V, Carp I, Blystiv T, Palchuk M, Kovalova N, \& Khrypko I. Assessment of emotional state and mental activity of 15-16 year-old boys and girls who had a low level of physical activity. Journal of Physical Education and Sport. 2019; 19:1022-1029. https://doi. org/10.7752/jpes.2019.s3147

11. Imas YV, Dutchak MV, Andrieieva OV, Kashuba VO, Kensytska IL, Sadovskyi 00. Modern approaches to the problem of values' for- 
mation of students' healthy lifestyle in the course of physical training. Physical education of students. 2018;22(4):182-9. DOI:10.15561/ 20755279.2018.0403

12. Hakman A, Andrieieva 0 , Bezverkhnia $H$ Moskalenko N, Tsybulska V, Osadchenko T, Filak Y Dynamics of the physical fitness and circumference sizes of body parts as a motivation for selfimprovement and self-control in students. Journal of Physical Education and Sport. 2020;20(1):116122. https://doi.org/10.7752/jpes.2020.01015

13. Kashuba VA, Futorny SM, Andreeva EV. Modern approaches to the health of students in the process of physical education. Phys. education of students. 2012;5:50-58.

\section{ІНФОРМАЦІЯ ПРО АВТОРІВ}

Гресь Марина https://orcid.org/0000-0002-5459-5236, gres.marina.95@ukr.net Андрєєва Олена Валеріївна https://orcid.org/0000-0002-2893-1224, olena.andreeva@gmail.com Національний університет фізичного виховання і спорту України 03150, Київ, вул. Фізкультури, 1

\section{INFORMATION ABOUT THE AUTHORS}

Hres Maryna https://orcid.org/0000-0002-5459-5236, gres.marina.95@ukr.net Andrieieva Olena https://orcid.org/0000-0002-2893-1224, olena.andreeva@gmail.com National University of Ukraine on Physical Education and Sport 03150, Kyiv, Fizkul'tury str., 1 